[Research Paper]

\title{
$\mathrm{ABS}$ 나노복합재료와 이를 적용한 내화창호시스템의 개발 - 파트 I: ABS 나노복합재료의 개발
}

\author{
강성욱 · 권민재 ${ }^{*}$ 최정윤 ${ }^{* *}$
}

한국건설생활환경시험연구원 건설본부 방재기술센터 책임연구원, ${ }^{*}$ 한국건설생활환경시험연구원 건설본부 방재기술센터 주임연구원,

**한국건설생활환경시험연구원 건설본부 방재기술센터 수석연구원

\section{Development of an ABS Nanocomposite Material and Its Application to a Fire-Resistant Glazing System - Part I: Development of an ABS Nanocomposite Material}

\author{
Sungwook Kang $\cdot$ Minjae Kwon ${ }^{*} \cdot J$. Yoon $\mathrm{Choi}^{* * *}$ \\ Senior Research Engineer, Fire Protection Technology Center, Korea Conformity Laboratories, \\ *Junior Research Engineer, Fire Protection Technology Center, Korea Conformity Laboratories, \\ ${ }^{* *}$ Principal Research Engineer, Fire Protection Technology Center, Korea Conformity Laboratories
}

(Received August 14, 2020; Revised September 7, 2020; Accepted September 7, 2020)

$$
\text { 요 약 }
$$

본 연구에서는 건축물의 구성재 중 하나인 커튼월구조 창호시스템의 저단열성 알루미늄 프레임 부분에 대해 가연 성이 개선된 고단열성 $\mathrm{ABS}$-나노클레이 복합재료(이하 나노복합재료)를 적용하여 건축물의 에너지 효율성과 화재안 전성 확보 모두에 기여하고자 한다. 파트 I에서는 $\mathrm{ABS}$ 의 가연성 개선을 위해 (i) 클레이를 나노 분산(CTAB / Mica)시 키고 (ii) 다공성 탄화발포 보호층을 형성시키는 팽창형 수지(Intumescent material)를 첨가한 나노복합재료를 개발한 다. 이 과정에서 클레이의 분산성을 높이기 위해 친수성인 클레이를 친유성으로 개질하였고, $\mathrm{ABS}$ 구성물의 극성을 높이기 위해 수지에 그라프트 공중합(ABS-g-MAH)을 시켰다. 개선된 성능 확인을 위해 X-ray diffraction (XRD), Transmission electron microscopy (TEM), Thermogravimetric analysis (TGA), Differential scanning calorimetry (DSC), Laser flash apparatus (LFA), Cone calorimeter 실험을 수행하였고 그 결과를 기반으로 창호시스템 프레임 내 적용을 위한 최적배합비로서 ABS-g-MAH : CTAB / Mica : Intumescent = $100: 5$ : 35 (phr)로 결정하였다. 파트 II에서는 연구실 단계에서 개발된 재료를 생산 단계로 스케일업하여 내화창호시스템 파일럿 모델을 제작하고 그 내화성능의 확인을 위해 벤치스케일 및 실스케일 내화실험하는 과정을 다룬다.

\section{ABSTRACT}

This study is focused on the development of a curtain-wall-type fire-resistant glazing system to contribute to both energy efficiency and fire safety of a building. The weakness of the aluminum frame on thermal insulation was supplemented by an ABS nanocomposite material with a superior thermal insulation performance. It contained (i) a maleic-anhydride-grafted ABS to improve the dispersion of clay, (ii) nanoscale clay, and (iii) intumescent material to retard the combustion on the exposed surface of the polymer. A series of X-ray diffraction, transmission electron microscopy, differential scanning calorimetry, LFA, and cone calorimetry tests were carried out to analyze the degree of improvement in flame retardancy and optimize the compound ratio. In Part II (the authors' companion paper), the ABS nanocomposite material based on the optimized compound ratio was scaled up for application to a fire-resistant glazing system in industries. Bench- and full-scale tests were performed to confirm the system's performances in terms of both thermal resistance and insulation.

Keywords : Fire-resistant glazing, Fire retardant polymer, Nanoclay, Flammability, Fire resistance test

\footnotetext{
† Corresponding Author, TEL: +82-43-210-8904, FAX: +82-43-210-8985, E-Mail: j.yoon.choi@kcl.re.kr (c) 2020 Korean Institute of Fire Science \& Engineering. All right reserved.
} 


\section{1. 서 론}

건축물에서 채광과 환기라는 순기능을 담당하는 창호는 전통적인 석재류(Masonry) 벽체에 비해 부족한 단열성능으 로 인해 건축물의 에너지효율 저감이라는 역기능을 수반한 다. 우리나라에서는 2010년대에 들어서며 본격적으로 에너 지소비총량제, 에너지효율등급 등 건축물의 에너지효율 향 상을 위한 정책 및 인증이 확대되어왔다. 이 기조에 발맞추 어 창호에 대해서도 건축물 외기에 접하는 곳에서 면적 $1 \mathrm{~m}^{2}$ 이상의 경우 2012년 7월부터 에너지효율등급제도가 시행 되고 있다. 창호의 일종인 커튼월 역시 건축물의 에너지효 율 향상이라는 동향으로 발전하고 있다. 이와 관련해서 한 국에너지공단은 커튼월 고효율인증제도 도입을 검토해왔 고 최근 이 정책이 시장 내 연착륙할 수 있도록 업계와의 교감을 나누고 있으며, 업계도 성능충족을 위해서 발빠르 게 움직이고 있다.

커튼월은 기둥, 보, 바닥판 등으로 이루어진 건축물 내력 구조체의 외부마감 시 적용하는 비내력 유리외장시스템을 의미하며, 개략적으로 유리와 프레임(Mullion and transom) 으로 구성된다. 이 기법은 건축물시공 시 외벽경량화, 작업 간소화, 공기단축화, 외관유려화 등의 장점을 제공한다. 그 러나 유리의 시공두께가 일반 외벽체에 비해 얇고 구조재 인 프레임의 재료로 주로 열전도율이 높은 금속을 사용하 므로 전반적인 단열성능에 약점이 있다. 이에, 관련 산학연 은 외기 노출 면적이 넓은 유리 부분의 성능향상 뿐만 아 니라 상대적으로 노출 면적이 작은 프레임 부분의 성능향 상에 대해서도 관심을 가져왔다 ${ }^{(1)}$.

건축물 에너지효율등급향상의 관점에서 커튼월을 포함 한 창호(이하 창호시스템)의 프레임 부분에 열전도율이 낮 고 기능성이 우수한 합성수지를 적절히 적용하는 것은 좋 은 방안이 될 수 있다. 그러나 간헐적으로 건축물 외벽이 관여된 대형 화재사고가 발생하고 있고 이러한 사고는 곧 외벽 위치의 창호시스템과 직접 연관되므로 프레임에 합성 수지를 적용할 때에는 화재안전성에 대한 고려가 반드시 필요하다 ${ }^{(2-3)}$.

본 연구에서는 건축물의 구성재 중 하나인 창호시스템이 건축물의 에너지효율성과 화재안전성 확보에 모두 기여할 수 있는 방안을 찾고자 한다. 단열성 확보를 위해 창호시스템 내 고분자수지(i.e. acrylonitrile-butadiene-styrene terpolymer, $\mathrm{ABS}$ ) 를 도입하였다. $\mathrm{ABS}$ 의 가연성 개선을 위해서는 일반 난연 제 첨가 시 연소과정에서 유해물질의 발생과 타 기능성의 저감을 피할 수 없으므로 이를 완화시킬 목적으로 클레이 를 개질하여 $\mathrm{ABS}$ 내 나노분산시켰다. 이렇게 가연성이 개 선된 고단열성의 $\mathrm{ABS}$-나노클레이 복합재료(이하 나노복합 재료)를 창호시스템 프레임에 적용하였다. 비록 커튼월구 조 창호시스템은 비내력 구조물이나, 건축물의 외벽 위치 에 시공되면 풍하중에 견딜 수 있는 구조적 안정성이 요구 되므로 프레임의 기본 재료를 알루미늄으로 결정하였고 일
부 강철로 보강하였다. 이 프레임을 유리세트와 결합시켜 결과적으로 적절한 수준의 단열성과 내화성을 동시에 확보 할 수 있는 파일럿 모델(커튼월 구조의 단일고정창호) 제작 을 목표로 설정하였다. 연구는 재료 개발에서부터 창호시 스템 제작에 이르기까지 다음의 일련의 과정을 거쳐 수행 되었다:

1) $\mathrm{ABS}$ 복합체 재료의 준비(파트 I);

2) $\mathrm{ABS}$ 수지 내 클레이 나노분산(파트 I);

3) 나노복합재료 가연성 개선을 위한 배합비 결정(파트 I);

4) 알루미늄-나노복합재료 프레임 개발(파트 II);

5) 창호시스템의 내화성능 및 단열성능 검토(파트 II).

본 지에서는 1)-3)에 해당하는 내용을 집중적으로 다룬 다. 참고로 커튼월에 대한 고효율인증제도와 시험방법은 정책화를 위한 논의가 현재 진행 중으로 일반창호 단열2 등급 정도 $\left(1.0-1.4 \mathrm{~W} /\left(\mathrm{m}^{2} \mathrm{~K}\right)\right)$ 의 열관류율을 검토 중이며, 커 튼월을 방화지구 내 설치할 경우에 한정하여 외벽 중 비내 력벽으로 연소할 우려가 없는 부분에 30 분 내화성능을 요 구하고 있다 ${ }^{(4-5)}$.

\section{2. 본 론}

\section{1 건축물 화재안전성에 대한 창호시스템 역할}

건축물의 화재안전성 확보를 위한 공학자들의 전략은 다음의 내용으로 대동소이하다 ${ }^{(6-7)}$ :

1) 화재의 성장을 제한하기 위해 내부 마감재료를 가연 성(Flammability), 화재성장률(Fire growth rate) 등의 정량화 된 물성을 이용하여 등급화 및 제한적용;

2) 건물 내 거주자의 대피시간을 확보하고 내부 화재확산 과 그에 따른 화재규모의 성장을 억제하기 위해 벽체, 슬래브 등을 이용한 방화구획화(Fire compartmentalization, Figure 1a);

3) 외벽을 통한 화재의 수직확산과 그에 따른 화재규모 확대와 인접건물로의 화재전이를 제한하기 위해 외장재의 가연성(혹은 화재성장률, 혹은 둘 다)과 부지경계 및 인접 건물과의 이격거리를 관리(Figure 1b);

4) 고온조건에서의 구조물 안정성(Stability) 확보를 위해 하중을 받는 구조체를 내화성(Fire resistance)에 대해 등급 화 및 제한적용.

창호시스템은 이 전략들 중 1)-3)에 관여된다. 그러므로 단열성 향상을 위해 합성수지를 프레임에 적용하기 앞서, 1)-3)의 전략에 가능한 한 차질이 생기지 않도록 창호시스 템에 요구할 수 있는 화재안전성능에 대해서 공학적 측면 과 정책적 측면에서 살펴볼 필요가 있다.

공학적 관점에서 살펴보면, 1), 3)과 관련해서, 유리의 경 우는 불연재이므로 가연성과 화재성장률에 대해 위험요인 이라는 지적을 피할 수 있으나, 프레임의 경우 합성수지가 적용되었다면 그 본연의 가연성질로 인해 위의 지적을 피 하긴 어려워 보이므로 가연성 개선이 필요하다. 2), 3)과 관 련해서, 화염은 가연성 내장재와 외장재를 가연물로 하여 


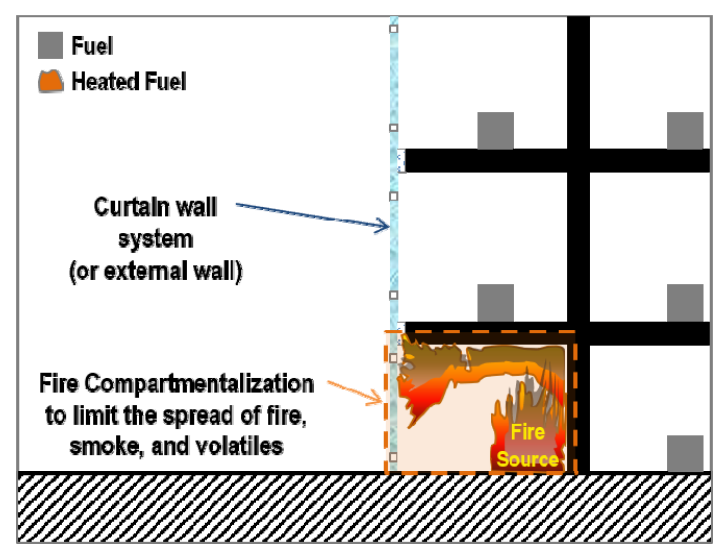

(a) Limitation of fire spread

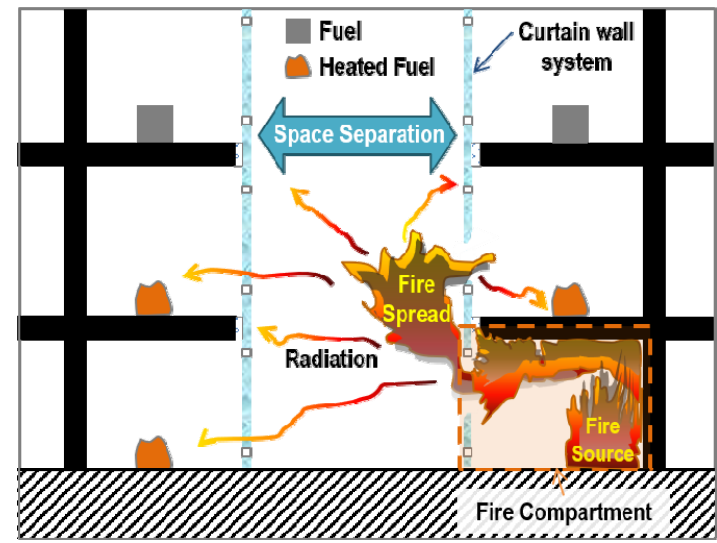

(b) External spread of fire on external walls and from one building to another

Figure 1. Schematics of fire compartmentalization and its failure.

각각 실내와 외벽으로 수평확산과 수직확산하게 된다. 이 때 방화구획을 넘어선 공간에서의 내/외장재 발화의 주요 요인은 창호시스템(혹은 문)이 파괴된 개구부를 통한 화염 분출이다 ${ }^{(8)}$. 이러한 확산현상의 발생을 지연시키기 위해서 는 방화구획 내 설치된 창호시스템이 구획 화재에 대응해 일정 시간동안 파손되지 않고 버틸 수 있는 내화성능이 필 요하다.

정책적 측면에서 살펴보면, 창호시스템의 화재안전 요구 성능에 대한 국내 법령들의 구체성은 아직 업계에 따라 해 석방향에 이견이 있을 만한 단계이다. 1), 3)과 관련해서, 불연재인 유리를 제외한 프레임 부분이 내/외부 마감재로 취급되어 가연성 관리를 받아야 될 지에 대한 이견이 존재 한다. 이는 사용된 프레임의 노출 면적, 부피, 질량 등이 전 체 내/외장재의 그것들에 비해 작은 편인데, 프레임 재료의 연소가 건축물 전반의 화재안전성에 얼마나 악영향을 미칠 지 혹은 무시할 만할지, 프레임 재료의 가연성과 화재성장 률에 대한 합리적인 제한치는 얼마일지 등에 대한 의문이 여전히 존재하기 때문이다. 2), 3)과 관련해서는, 창호시스 템이 외벽으로 취급되어 내화성 관리를 받아야 될 지에 대 해 이견이 존재한다. 이에, 2017년 10 월 국토교통부는 건축

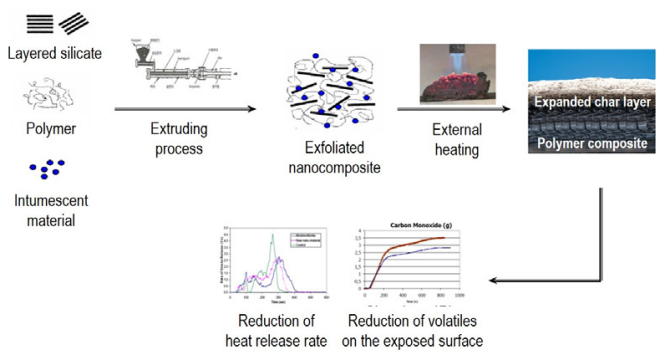

Figure 2. A process to improve the flammability of polymer composites.

법령운영지침을 통해 커튼월에 한정해서 방화지구 내 건축 물에 설치하는 경우에만 외벽으로 취급하고 내화구조로 하 는 것이 타당함을 시달한 바가 있다 ${ }^{(4)}$. 요약하자면, 위 의문 들이 해소되어야 정책화에 대한 산.학.연·관 간의 합의가 가능할 것으로 보이며 이를 위한 추가 연구와 논의가 필요 한 상황이다.

\section{2 가연성 개선 $\mathrm{ABS}$ 복합체 재료의 준비}

자동차, 전자기기 등의 부품 소재로 널리 사용되고 있는 $\mathrm{ABS}$ 수지는 다른 고분자들과 마찬가지로 가연성이라는 약 점을 가지고 있다. 고분자의 연소를 지연시키기 위한 방안 으로 난연제를 첨가하는 것이 일반적이며 이들의 세부 지 연 매커니즘은 다음으로 구분할 수 있다(9-10):

1) 첨가제가 고분자의 열분해 경로를 바꾸어 가연가스 미생성;

2) 첨가제가 라디컬과 반응함으로서 라디컬 연소매커니 즘 방해;

3) 첨가제의 흡열반응을 통한 연소과정 지연;

4) 첨가제가 고분자 표면에서 탄화층의 형성을 촉진함으 로서 열전달 및 고분자 열분해 지연.

이와 관련해서 난연성능이 우수하다고 알려진 할로겐계 난연제는 환경규제로 인해 사용이 제한적이며 친환경으로 알려진 무기수화물계 난연제는 첨가 시 기계적 물성 저하 라는 부작용이 예상된다 ${ }^{(10-11)}$. 이에 본 연구에서는 네 번째 방법을 기본으로 하여 (i) 친환경 소재인 클레이를 $\mathrm{ABS}$ 수 지 내 나노 크기로 분산시키고, (ii) 고온 조건에서 다공성 탄 화발포층을 형성함으로서 연소를 억제하는 역할을 하는 팽 창형 수지(Intumescent material)를 첨가하는 방법을 통하여 $\mathrm{ABS}$ 복합체의 가연성을 개선하고자 하였다(Figure 2 참조).

고분자는 타 재료들에 비해 상대적으로 낮은 온도조건 에서 열분해(Thermochemical decomposition)가 발생한다. 이 과정에서 생성되는 휘발성 유기저분자물질(i.e. volatile)은 고분자 제품의 노출표면으로 이동해서 외부산소와 만나게 되고 연소반응이 진행된다. 이러한 매커니즘은 고분자 소 재 내 클레이의 나노 분산화(Exfoliation)를 통해 클레이의 비표면적을 최대화시킴으로서 지연될 수 있다.

클레이 분산성은 용매에 대한 관련 화학물질들의 친밀 성에 영향을 받는다. 친유성(Hydrophobic)인 고분자 내에 
친수성(Hydrophilic)인 클레이의 분산성을 높이기 위해서는 클레이의 표면을 친유성으로 개질하는 것이 필요하다. 본 연구에서는 smectite 클레이인 Na-fluorine mica (이하 mica) 에 대한 계면활성제로 긴 알킬(Alkyl) 사슬을 가지고 있는 암모늄계열 Cetyltrimethyl ammonium bromide (CTAB)를 선 정하였다. 알킬 사슬의 양이온성 Head group은 음이온성 mica의 내부층 공간(Interlayer space)에 효과적으로 삽입될 수 있으며 사슬의 Tail group은 친유성이어서 클레이 표면 의 성향을 친유성으로 개질할 수 있다. $\mathrm{CTAB}$ 와 mica의 결 합은 mica 내부층 간의 거리(i.e. Basal spacing)를 넓히는 역 할도 하므로 다층구조인 mica가 나노두께의 낱장들로 분리 되어 $\mathrm{ABS}$ 수지 내 골고루 분산되는 확률을 높일 수 있다. 이에 대한 세부 방법과 고찰은 기 논문에서 다뤄졌다 ${ }^{(12)}$.

$\mathrm{ABS}$ 수지 내 클레이의 분산성을 높이기 위한 또다른 방안으 로 $\mathrm{ABS}$ 구성물의 극성(Polarity)을 높이는 방법이 있다. $\mathrm{ABS}$ 수 지는 Polyacrylonitrile (PAN), Polybutadiene (PBD), Polystyrene (PS), Styrene-acrylonitrile copolymer (SAN)로 구성되는데. 클 레이 분산 시 클레이 층들은 극성이 높은 SAN에 주로 위치 한다 ${ }^{(13)}$. 이에, 본 연구에서는 $\mathrm{PBD}$ 에도 클레이 층들을 분포 시키기 위해 기능성 단량체(Functional monomer)인 Maleic anhydride (MAH)를 butadiene이 포함된 ABS 수지에 그라프 트 공중합(Graft copolymerization)시킴으로서 PBD의 극성을 개선시킨 $\mathrm{ABS}$ 수지(i.e. ABS-g-MAH)를 사용하였다(13-15).

팽창형 수지(Intumescent material)는 고온에 노출된 고분 자의 표면에 다공성 탄화발포층(Porous carbonaceous char layer)을 형성하고 이는 열 유입에 대한 보호막 뿐만 아니 라 표면생성 가연가스와 외부산소의 접촉에 대한 방해막으 로 작용하여 연소(Combustion)의 진행을 억제한다. 팽창형 수지는 통상 3 개의 주요 물질로 구성된다: (i) Acid source; (ii) Carbonization agent; (iii) Blowing agent. 본 연구에서는 위의 주요 물질로 각각 Ammonium phosphate monobasic (APP), Mono-pentaerythritol (PER), Melamine (MEL)을 선택 하여 구성 비율을 $\mathrm{APP}: \mathrm{PER}: \mathrm{MER}=3: 1: 1$ 로 결정하였고 이 에 대한 고찰은 기 논문에서 다뤄졌다 ${ }^{(1)}$.

\section{$2.3 \mathrm{ABS}$ 수지 내 클레이 나노분산 및 성능확인}

$\mathrm{ABS}$-나노클레이 복합재료(이하 나노복합재료)를 창호시 스템의 프레임에 적용하기 위해서는 대량생산이 필요하며, 이를 위해서는 앞서 준비된 재료들을 실험실 단계에서 다 양한 비율로 합성하고 그들의 성능을 확인함으로서 적용 목적에 맞는 최적 배합을 결정하는 과정이 필요하다. 이 과 정에서 사용된 나노복합재료의 구성과 재료들의 구입처는 각각 Table 1과 2에 정리하였다.

순수 유기화된 클레이(i.e. CTAB / Mica)에 대비하여 CTAB / Mica 함량 변화와 MAH의 적용에 따른 고분자 내 클레이 층의 분산 정도를 확인하기 위해 X-ray 회절분석(XRD)을 수행하였고 그 결과는 Figure 3 에 나타나 있다. 고분자 내 클레이를 압출 분산시킨 복합체들의 결과를 살펴보면, 순
Table 1. Specimens

\begin{tabular}{c|l}
\hline No. & Composition of ABS Nanocomposite \\
\hline \hline 1 & Neat ABS \\
\hline 2 & ABS and CTAB / Mica 1 phr \\
\hline 3 & ABS and CTAB / Mica $3 \mathrm{phr}^{*}$ \\
\hline 4 & ABS and CTAB / Mica $5 \mathrm{phr}^{*}$ \\
\hline 5 & Neat ABS-g-MAH \\
\hline 6 & ABS-g-MAH and CTAB / Mica 1 phr \\
\hline 7 & ABS-g-MAH and CTAB / Mica $3 \mathrm{phr}^{*}$ \\
\hline 8 & ABS-g-MAH and CTAB / Mica $5 \mathrm{phr}^{*}$ \\
\hline
\end{tabular}

"phr: parts per hundred resin

Table 2. Materials used and Their Manufacturers.

\begin{tabular}{c|c}
\hline Material & Manufacturer \\
\hline \hline ABS & LG Chem Ltd. in Korea \\
\hline ABS-g-MAH & Polyram in Israel \\
\hline Mica & Co-Op Chemicals in Japan \\
\hline $\mathrm{CTAB} / \mathrm{APP} /$ PER / MEL & Sigma-Aldrich in Korea \\
\hline
\end{tabular}

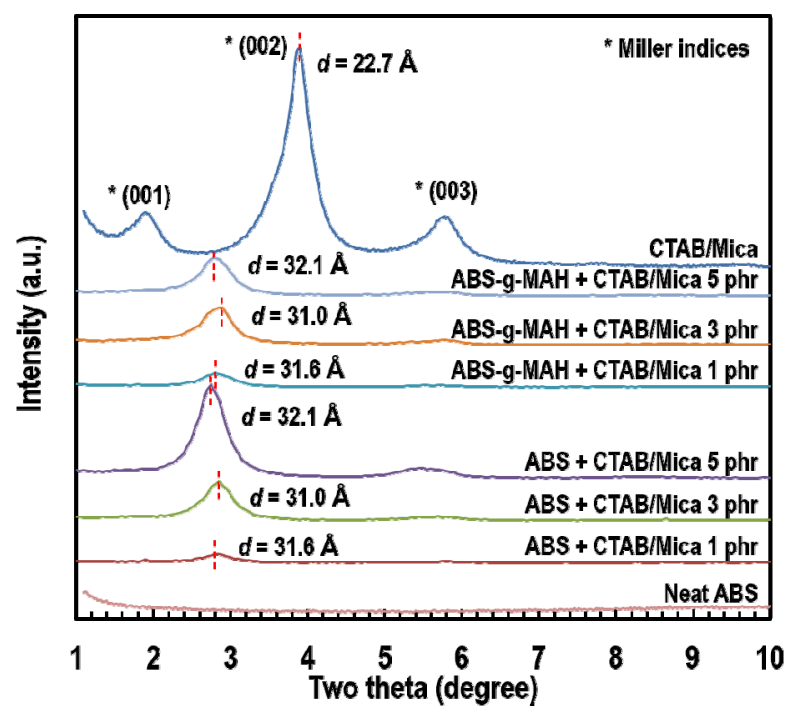

Figure 3. XRD profiles of ABS / nanoclay composites.

수 유기화 클레이에서 확인된 $1.9^{\circ}$ 에서의 (001) peak가 사라 졌고 $3.9^{\circ}$ 에서의 (002) peak 대신에 약 $2.8^{\circ}$ 근처에의 새로운 (002) peak들이 확인되었다. 이는 CTAB / Mica의 Basal spacing (d)이 약 $22.7 \AA$ 에서 약 $32.1 \AA$ 로 넓혀졌으므로 분산성이 좋아졌음을 의미한다. MAH 적용에 따른 분산성을 살펴보 면, $\mathrm{ABS}$ 를 사용했을 때의 intensity에 비해 gABS의 intensity 가 낮은 것으로 보아 나노클레이의 분산도가 향상되었음을 확인하였다.

나노복합재료의 클레이 분산성을 시각적으로 확인하기 위해 Transmission electron microscopy (TEM)을 이용하여 


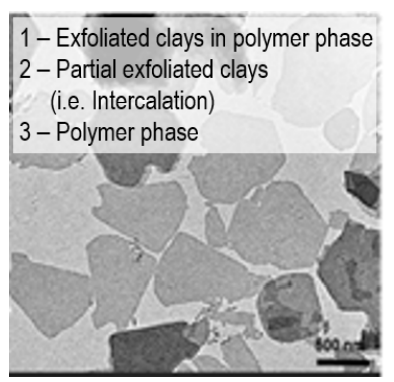

(a) CTAB / Mica

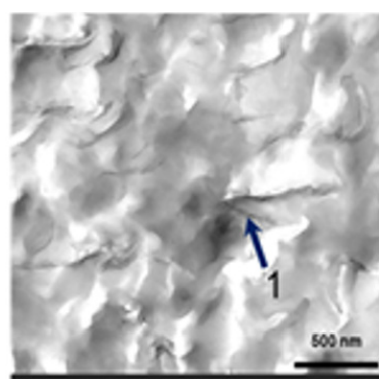

(e) $\mathrm{ABS}+$

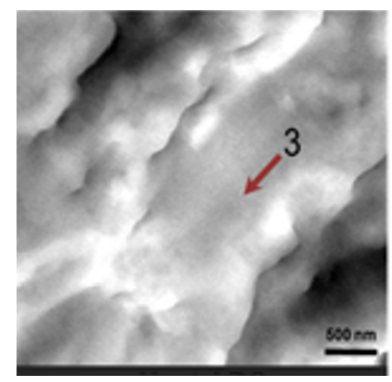

(b) Neat ABS

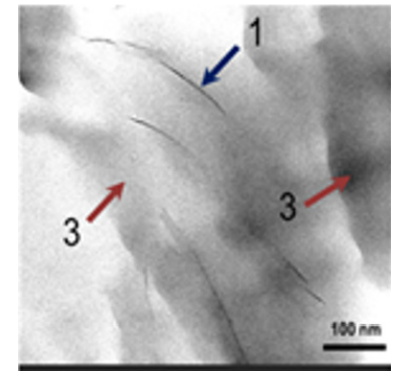

(f) ABS-g-MAH +

CTAB / Mica 1 phr

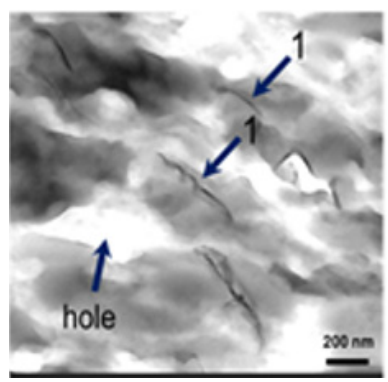

(c) $\mathrm{ABS}+$

CTAB / Mica 1 phr

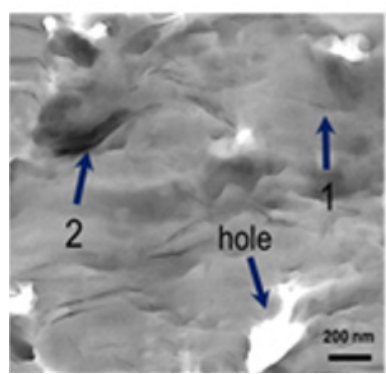

(g) ABS-g-MAH +

CTAB / Mica 3 phr

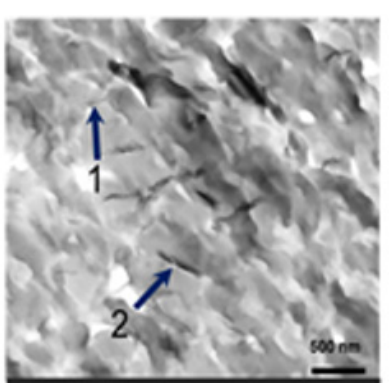

(d) $\mathrm{ABS}+$

$\mathrm{CTAB} /$ Mica $3 \mathrm{phr}$

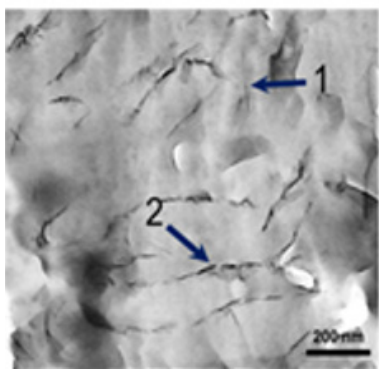

(h) ABS-g-MAH +

CTAB / Mica 5 phr

Figure 4. TEM images of ABS nanocomposites.

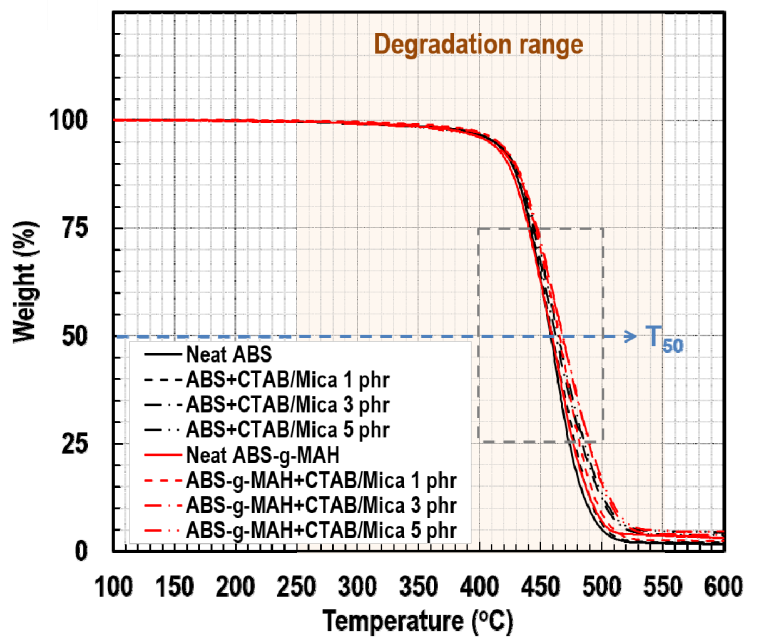

(a) Mass loss in a degradation range

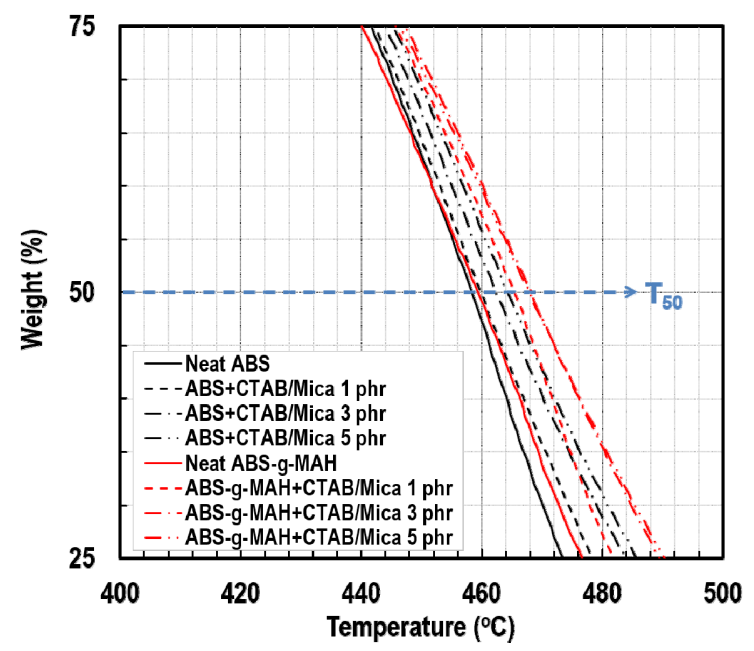

(b) Zoomed in for a close-up

Figure 5. Temperature-mass profiles at a heating rate of $30{ }^{\circ} \mathrm{C} / \mathrm{min}$.

Figure 4의 이미지를 추출하였다. 번호 $1,2,3$ 은 각각 고분 자 상 내에 나노분산된 클레이, 부분 나노분산된 클레이, 고분자 상을 의미한다. $\mathrm{CTAB} / \mathrm{Mica}$ 의 크기는 길이 $~ 650$ $\mathrm{nm}$, 폭 $100 \mathrm{~nm}$, 두께 $\sim 1 \mathrm{~nm}$ 로 관찰되었다(Figure $4 \mathrm{a}$ ). 고분 자(ABS \& ABS-g-MAH) 상에 CTAB / Mica 1 phr가 분산된 경우는 1 번 클레이층이 주로 관찰되었고 클레이의 함량이 늘어나면서 2 번 클레이 층도 종종 관찰되었다. 이는 나노 복합재료의 대량생산을 위해 선택한 압출 방법에서는 혼합 시 클레이의 함량이 높을수록 고분자가 나노클레이 층 사
이로 삽입될 수 있는 반응시간이 충분치 않아 분산성이 다 소 감소하는 경향을 보임을 의미한다.

나노복합재료의 배합비에 따른 열안정성을 확인하기 위해 Thermogravimetric analysis (TGA) 장비를 이용하여 Figure 5 에 나타낸 바와 같이 온도별 질량감소를 측정하였다. 열분 해가 발생하는 온도구간은 약 $250-550{ }^{\circ} \mathrm{C}$ 이었고 배합비별 질 량 감소는 전반적으로 유사한 추세로 관찰되었다(Figure 5a). 이는 클레이의 질량이 고분자 상에 비해 미량이므로 고분 자 상의 질량변화 추세에 큰 영향을 주지 못함을 의미한다. 


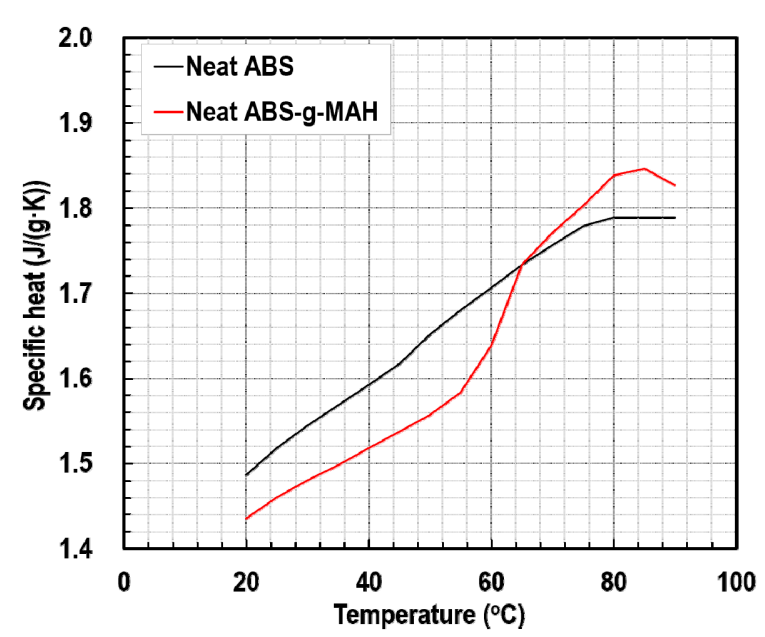

Figure 6. Temperature-specific heat profiles of neat polymers.

질량이 $50 \%$ 감소했을 때의 온도 $\left(T_{50}\right)$ 를 살펴보면, ABS-g$\mathrm{MAH}$ 를 적용했을 때와 $\mathrm{CTAB} / \mathrm{Mica}$ 함량이 높을수록 열 안정성이 다소 좋아짐을 확인하였다(Figure $5 \mathrm{~b}$ ).

$\mathrm{ABS}$ 나노복합재료의 온도증가율 및 가연가스를 생성하게 되는 열분해 온도구간까지 도달하는 시간에 영향을 주는 열물 성으로는 비열(Specific heat)과 열전도도(Thermal conductivity) 가 있으며, 가연성 개선 측면에서는 비열이 높을수록 열전 도도가 낮을수록 유리하다. 고분자 나노복합재료에서 가장 높은 비율을 차지하는 고분자 상(ABS or ABS-g-MAH phase) 의 비열을 확인하기 위해 Differential scanning calorimetry (DSC)를 이용하여 Figure 6과 같이 비열을 측정하였다. 고 분자 상의 비열은 $1.435-1.846 \mathrm{~J} /(\mathrm{g} \cdot \mathrm{K})$ 범위에 있음을 확인 하였다.

$\mathrm{ABS}$ 나노복합재료의 열전도도는 Laser flash apparatus (LFA)를 이용하여 열확산도(Thermal diffusivity)를 측정한 후 앞서 얻어진 비열을 적용하여 계산하였으며 Figure 7 에 나타내었다. 고분자 상에 클레이가 분산되면 순수 고분 자 상보다 다소 높은 열전도도를 가지게 되는 경향을 확인 하였는데. $1 \mathrm{phr}$ 의 클레이를 분산시킬 때보다 $3,5 \mathrm{phr}$ 일 때 작은 규모로 열전도성이 증가하였다. 고분자 상에 따른 열 전도도 변화를 살펴보면 $\mathrm{ABS}$ 를 사용했을 때보다 ABS-g$\mathrm{MAH}$ 를 사용했을 때 전반적으로 낮은 열전도도를 가짐을 확인하였다. 감소폭은 $1 \mathrm{phr}$ 의 클레이를 분산시켰을 때 $19.8 \%$ 로 가장 컸으나 절대값이 $0.207 \mathrm{~W} /(\mathrm{m} \cdot \mathrm{K})$ 로 여전히 가 장 높았으며, $3 \mathrm{phr}$ 를 분산시켰을 때 가연성 개선측면에서 감소폭과 절대값이 모두 적절하였다.

가연성 개선 관점에서 나노복합재료의 구성에 따른 주요 성능(열안전성, 비열, 열전도도) 변화를 검토한 결과, ABS-g$\mathrm{MAH}$ 상 내 $3 \mathrm{phr}$ 내지 $5 \mathrm{phr}$ 클레이를 나노분산시키는 것 이 적합하였다.

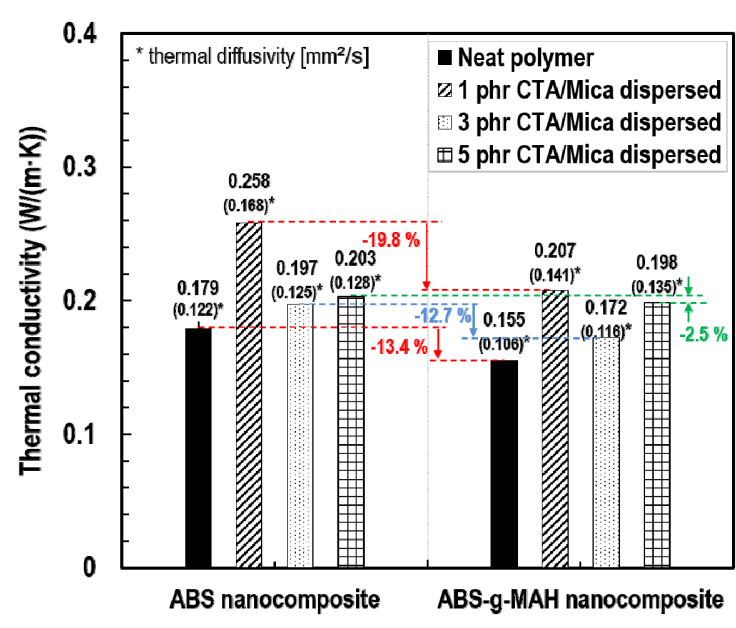

Figure 7. Thermal conductivity of ABS nanocomposites.

\section{4 나노복합재료 최적 배합비 결정}

가연물은 일련의 열적과정(열분해-기화-발화-연소)의 결 과물로 빛과 열을 발산한다. 구획화재에서 이 에너지는 가 스층 및 구조체의 온도를 증가시키고 이 현상은 발화원 외 의 구획 내 다른 가연물들의 추가연쇄발화와 그로 인한 플 래쉬오버(Flashover) 발현에까지 영향을 미치게 된다. 이와 같은 재료 연소에 의한 발열에너지의 정도는 전통적으로 산소소모법(17)을 이용한 열방출률(Heat release rate, HRR)로 표현된다.

본 연구에서도 나노복합재료의 가연성 개선에 대한 주 요 판단기준으로 앞 절에서 검토한 열안전성, 열용량, 열전 도도 뿐만 아니라 최대 열방출률(Peak heat release rate, $\mathrm{pHRR}$ )과 총 열방출량(Total heat released, THR)을 이용하고 자 하며 이들은 KS F 5660-1에 따른 콘칼로리미터를 사용 하여 측정되었다(18). 이를 통해서 나노복합재료의 주요 구 성물인 $\mathrm{ABS}$, 클레이, 팽창형 수지 간의 최적 배합비를 결 정하고자 하였다. 변수는 (i) 고분자 그라프트 공중합, (ii) 나노클레이 첨가율, (iii) 팽창형 수지 첨가율, (iv) 나노복합 재료 두께로 설정하였고 이를 반영하여 제작된 총 13 개의 실험체들의 세부구성은 Table 3에 정리하였다.

히터 하단과 실험체의 상부 가열표면과의 수직 거리가 $25 \mathrm{~mm}$ 인 위치에 $100 \mathrm{~mm} \times 100 \mathrm{~mm}$ 크기의 실험체를 고정 시키고, 실험체의 가열표면에 $50 \mathrm{~kW} / \mathrm{m}^{2}$ 의 복사열류량을 입사시켰다. 본 실험은 연소시 열방출률을 측정하기 위한 목적이므로 복사열 노출 조건에서 외부발화원(i.e. electric spark)을 통해 실험체를 발화시켰다.

Figure 8은 실험체별 시간에 따른 열방출률 변화를 보여준 다. 검은색, 붉은색은 각각 고분자 상이 $\mathrm{ABS}, \mathrm{ABS}-\mathrm{g}-\mathrm{MAH}$ 인 실험체들을 의미하며, 파란색은 팽창형 수지가 첨가된 실 험체들을 보여준다. 녹색은 가연성이 가장 낮은 실험체를 의미한다. 전반적으로 검은색, 붉은색, 파란색 순으로 그래 프의 높이가 낮아지고 폭이 넓어져 난연성능이 좋아지는 
Table 3. Specimens Tested with the Cone Calorimeter

\begin{tabular}{c|c|c|c|c|c|c|c|c|c}
\hline No. & Name & $\begin{array}{c}\text { Thick-ness } \\
(\mathrm{mm})\end{array}$ & $\begin{array}{c}\text { Initial mass } \\
(\mathrm{g})\end{array}$ & $\begin{array}{c}\text { Polymer phase } \\
\left(\mathrm{phr}^{*}\right)\end{array}$ & $\begin{array}{c}\text { Nano-clay } \\
\left(\mathrm{phr}^{*}\right)\end{array}$ & $\begin{array}{c}\text { Intumescent } \\
\left(\mathrm{phr}^{*}\right)\end{array}$ & $\begin{array}{c}\text { Residue } \\
(\mathrm{g})\end{array}$ & $\begin{array}{c}\mathrm{pHRR} \\
\left(\mathrm{kW} / \mathrm{m}^{2}\right)\end{array}$ & $\begin{array}{c}\text { THR } \\
\left(\mathrm{MJ}^{2} \mathrm{~m}^{2}\right)\end{array}$ \\
\hline \hline 1 & A-C0-I0 & 3.98 & 39.60 & {$[$ ABS] 100} & 0 & 0 & 0.40 & 1558.53 & 142.10 \\
\hline 2 & A-C1-I0 & 3.92 & 39.60 & {$[$ ABS] 100} & 1 & 0 & 2.70 & 1010.79 & 135.50 \\
\hline 3 & A-C3-I0 & 3.93 & 39.80 & {$[$ ABS] 100} & 3 & 0 & 1.30 & 687.00 & 136.80 \\
\hline 4 & A-C5-I0 & 3.94 & 40.10 & {$[$ ABS] 100} & 5 & 0 & 1.20 & 598.02 & 138.10 \\
\hline 5 & gA-C0-I0 & 3.88 & 39.40 & [ABS-g-MAH] 100 & 0 & 0 & 0.60 & 1042.82 & 134.00 \\
\hline 6 & gA-C1-I0 & 3.92 & 39.60 & [ABS-g-MAH] 100 & 1 & 0 & 3.50 & 949.72 & 138.90 \\
\hline 7 & gA-C3-I0 & 3.92 & 39.60 & [ABS-g-MAH] 100 & 3 & 0 & 2.00 & 594.36 & 136.90 \\
\hline 8 & gA-C5-I0 & 3.90 & 40.10 & [ABS-g-MAH] 100 & 5 & 0 & 2.10 & 572.22 & 138.30 \\
\hline 9 & gA-C3-I25 & 4.00 & 44.19 & [ABS-g-MAH] 100 & 3 & 25 & 7.09 & 480.35 & 94.90 \\
\hline 10 & gA-C5-I25 & 4.00 & 43.41 & [ABS-g-MAH] 100 & 5 & 25 & 6.61 & 463.53 & 97.70 \\
\hline 11 & gA-C5-I30-1 & 3.98 & 42.70 & [ABS-g-MAH] 100 & 5 & 30 & 7.00 & 425.71 & 90.40 \\
\hline 12 & gA-C5-I30-2 & 2.00 & 26.07 & [ABS-g-MAH] 100 & 5 & 30 & 3.47 & 545.34 & 54.60 \\
\hline 13 & gA-C5-I35 & 3.99 & 43.00 & [ABS-g-MAH] 100 & 5 & 35 & 8.10 & 375.55 & 81.10 \\
\hline
\end{tabular}

"phr: parts per hundred resin

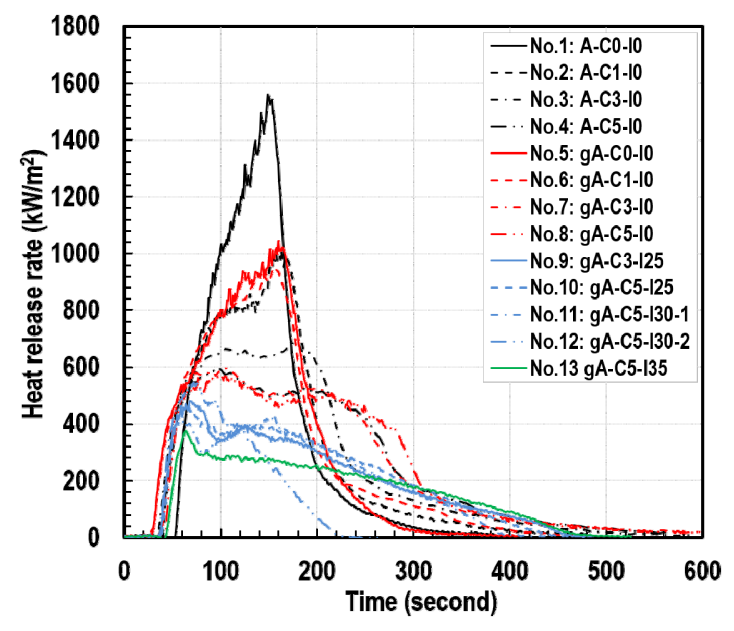

Figure 8. Time dependent heat release rate profiles of specimens.

\section{추세를 보였다.}

실험체 간 $\mathrm{pHRR}$ 과 THR의 값 비교는 Figure 9에서 드러 난다. 전반적으로 두 값 모두 고분자 상이 $\mathrm{ABS}$ 일 때보다 ABS-g-MAH일 때 낮은 경향을 보여주었다. pHRR의 경우, 클레이의 함량이 증가할수록 감소하는 경향을 보였고 그 저감률은 $\mathrm{ABS}$ 상일 경우 더 컸으나 절대값은 $\mathrm{ABS}-\mathrm{g}-\mathrm{MAH}$ 상일 때 더 낮았다. 반면, 클레이 함량 증가에 따른 THR 변 화는 명확한 규칙성은 보이지 않았으나 ABS-g-MAH 상에 서 절대값이 다소 낮았다.

팽창형 수지의 영향력은 Figure 10에서 명확히 드러난다. 팽창형 수지가 첨가된 실험체들의 $\mathrm{pHRR}$ 과 THR은 첨가되 지 않은 실험체(붉은색)에 비해 낮은 경향을 보였으며, 특 히 THR값이 현저히 낮아졌다. 이는 Table 3의 잔여물량

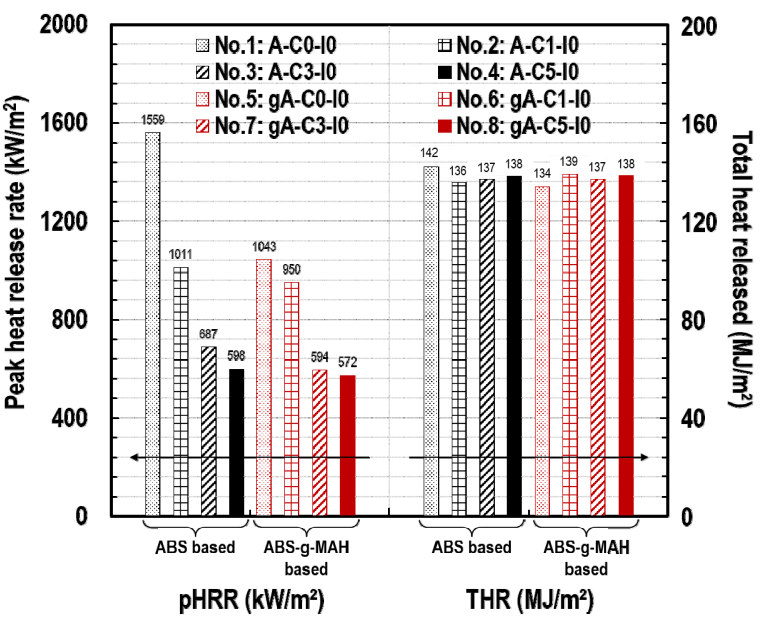

Figure 9. Peak heat release rate and total heat released of specimens.

(Residue)에서 확인할 수 있듯이 팽창형 수지가 탄화발포층 보호막을 형성하여 급격한 연소를 막았을 뿐만 아니라 열 전달을 지연시켜 가연가스의 생성을 방해하였다(Figure 11 참조). 이러한 매커니즘으로 인해 Figure 8의 No.13 그래프 에서처럼 총 연소시간이 길어졌다. 마지막으로 동일한 배 합비 조건에서 두께가 각각 $2 \mathrm{~mm}, 4 \mathrm{~mm}$ 인 실험체 No.12와 No.13을 살펴보면, No.13의 pHRR이 더 높게 관찰되었다. 이는 $2 \mathrm{~mm}$ 의 두께가 실험체 표면에 탄화층을 생성하기에 충분치 않아 보호막 역할이 미비했던 것으로 판단된다.

\section{3. 결 론}

본 연구에서는 커튼월구조 창호시스템의 알루미늄 프레 


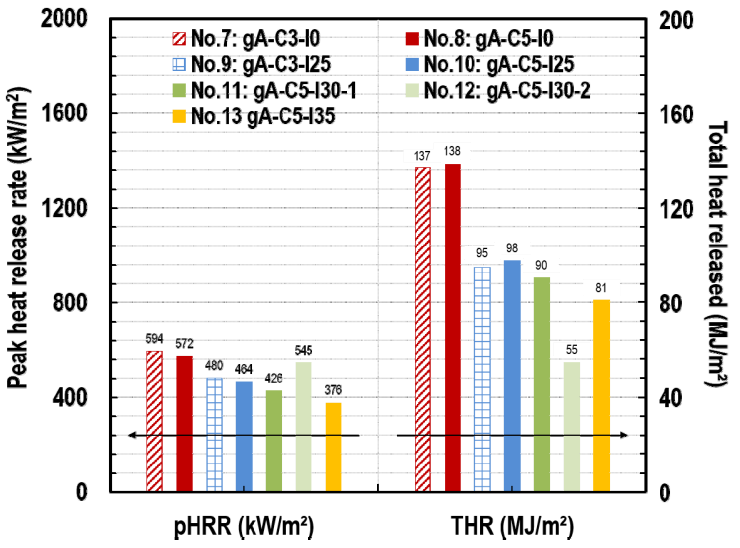

Figure 10. Peak heat release rate and total heat released of specimens.

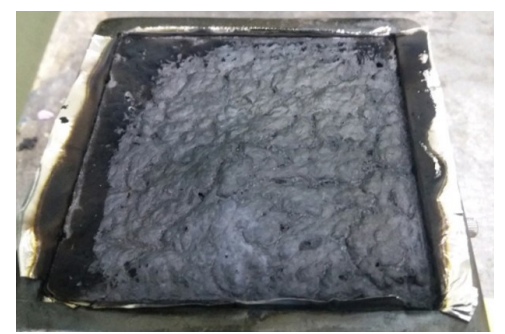

(a) No. 8: gA-C5-I0

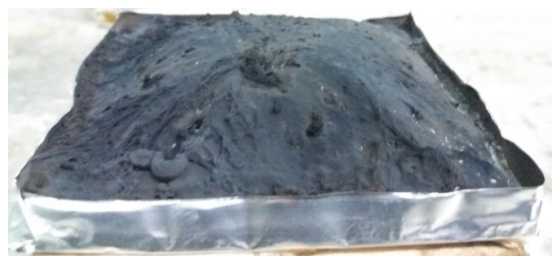

(b) No. 13: gA-C5-I35

Figure 11. Photos of specimens.

임 부분의 단열성 개선을 위해 $\mathrm{ABS}$ 수지를 적용하는 과정 에서 고분자 본연의 약점인 가연성을 개선하고자 하였다.

이를 위해 고분자 상 내 클레이를 나노 분산시켰다. 친수성 클레이를 친유성으로 개질(i.e. CTAB / Mica)하였고 고분자 상에 Maleic anhydride를 그라프트 공중합(i.e. ABS-g-MAH)시 켜 분산성을 높이고자 하였다. $\mathrm{XRD}$ 와 $\mathrm{TEM}$ 을 통해 $\mathrm{ABS}-$ $\mathrm{g}-\mathrm{MAH}$ 에 CTAB / Mica가 적절히 분산됨을 확인하였다. 그 외 열안정성, 비열, 열전도성을 측정 및 분석하여 ABS-g$\mathrm{MAH}$ 상 내 $3 \mathrm{phr}$ 내지 $5 \mathrm{phr}$ 의 클레이를 나노 분산시키는 것이 적절하다고 판단하였다.

또한 클레이가 나노 분산된 고분자 상에 팽창형 수지를 첨가하여 고분자 표면에서의 연소 지연을 활성화하고자 하 였다. Cone calorimeter를 이용하여 최대 열방출률과 총열방 출량을 측정함으로서 고분자 그라프트 공중합, 나노클레이 첨가율, 팽창형 수지 첨가율, 두께의 영향을 분석하였다. 결과적으로 공중합과 나노클레이 및 팽창형 수지 첨가는 가연성을 명확히 개선시켰다. 나노클레이 첨가율 $3 \mathrm{phr}$ 와 5 $\mathrm{phr}$ 는 유사한 개선성능을 보였으며, 팽창형 수지는 타 기능 성에 문제없는 수준에서는 다량 첨가될수록 좋은 성능을 보였다.

실험 결과를 기반으로, 공장 생산 단계에서의 커튼월구 조 창호시스템 파일럿 모델 제작을 위한 최적 배합비를 ABS-g-MAH:CTAB / Mica:Intumescent = 100:5:35 (phr)로 결 정하였다. 이 연구의 파트 II에서는 선정된 배합비로 생산 된 $\mathrm{ABS}$ 나노복합재료를 이용한 창호시스템 제작과 성능확 인 실험에 대한 내용을 다룬다.

\section{후 기}

이 연구는 2020년도 산업통상자원부 및 산업기술평가관 리원(KEIT)과 소방청 및 산업기술평가관리원(KEIT) 연구 비 지원에 의한 연구임(과제번호: 10080375와 20008021).

\section{References}

1. J. Song and D. Shin, "Examples of Curtain Wall Systems with High Performance of Thermal Insulation", Korean Ins. of Archi. Sustain. Environ. Building Systems, Vol. 14 No. 1, pp. 34-41 (2020).

2. H. Song, J. G. Lee, Y. S. Chu, H. W. Shin, S. K. Seo, C. W. Oh, J. Y. Lim, Y. A. Goo et al., "Development of Fire Resistant Curtain Wall System”, Korea Institute of Ceramic Engineering and Technology (2011).

3. J. S. Lee, H. C. Yim, B. H. Cho and H. Y. Kim, "An Experimental Study on Fire Resistance Performance of Curtain-wall System with Steel-aluminum Hybrid Frame", Journal of Korean Institute of Fire Science \& Engineering, Vol. 25 No. 6, pp. 104-111 (2011).

4. Ministry of Land, Infrastructure and Transport, "Regulations on Finishing Materials for External Walls of Buildings in a Fire Protection District" (2017).

5. Ministry of Land, Infrastructure and Transport, "[Appendix 1] Classification of Fire Resistant Structures" Regulations on Egress and Fire Protective Structures of a Building (2019).

6. T. Z. Harmathy, "Fire Safety: Science and Engineering", ASTM Special Tehcnical Publication 882, Philadelphia, USA (1985).

7. P. Thureson, B. Sundstrom, E. Mikkola, D. Bluhme, A. S. Hansen and B. Karlsson, "The use of Fire Classification in the Nordic Countries - Proposals for Harmonisation", SP Report 2008:29, SP Techinical Research Institute of Sweden (2008).

8. B. H. Lee, S. H. Jin, H. W. Kim and Y. J. Kwon, "An Experimental Study on the Fire Risk Assessment of Windows by Material", J. Korean Soc. Hazard Mitig., Vol. 19 No. 4, 
pp. 19-27 (2019).

9. M. Suzuki and C. A. Wilkie, "The Thermal Degradation of Acrylonitrile-butadiene-styrene Terpolymer Grafted with Methacrylic Acid", Poly. Deg. Stab., Vol. 47, pp. 223-228 (1995).

10. A. B. Morgan and J. W. Gilman, "An Overview of Flame Retardancy of Polymeric Materials: Application, Technology, and Future Directions", Fire and Materials, Vol. 37, pp. 259-279 (2013).

11. T. S. Hwang, B. J. Lee, Y. K. Yang, J. H. Choi and H. J. Kim, "The R\&D Trands of Polymer Flame Retardants", Prospctives of Industrial Chemistry, Vol. 8 No. 6, pp. 36-53 (2005).

12. H. J. Ryu, N. T. Hang, J. H. Lee, J. Y. Choi, G. Choi and J. H. Choi, "Effect of Organo-smectite Clays on the Mechanical Properties and Thermal Stability of EVA Nanocomposites", Applied Clay Science, Vol. 196, 105750 (2020).

13. H. Ma, Z. Xu, L. Tong, A. Gu and Z. Fang, "Studies of ABS-graft-maleic Anhydride / clay Nanocomposites: Morphologies, Thermal Stability and Flammability Properties", Poly. Deg. Stab., Vol. 91, pp. 2951-2959 (2006).
14. B. Madhusudhan Rao, P. Raghunath Rao and B. Sreenivasulu, "Grafting of Maleic Anhydride onto Acrylonitrile-butadienestyrene Terpolymer: Synthesis and Characterisation", PolymerPlastics Technology Engineering, Vol. 38 No. 5, pp. 967977 (1999).

15. R. Qi, J. Qian and C. Zhou, Modification of acrylonitrilebutadiene-styrene Terpolymer by Grafting with Maleic Anhydride in the Melt: I. Preparation and Characterization, Journal of Applied Polymer Science, Vol 90, pp. 1249-1254 (2003).

16. H. Kim, J. W. Park, J. H. Lee, S. W. Jang, H. J. Kim, Y. Choi, J. H. Choy and J. H. Yang, "Clay-organic Intumescent Hybrid System for the Synergetic Flammability of Polymer Nanocomposites", J. of Thermal Analysis and Calorimetry, Vol. 132 (2018).

17. D. Drysdale, "An Introduction to Fire Dynamics", John Wiley, \& Sons Ltd., Chichester, UK (2005).

18. KS F ISO 5660-1, "Reaction to Fire Test - Heat Release. Smoke Production and Mass Loss Rate - Part 1 : Heat Release Rate (Cone Calorimeter Method)", Korea Standards and Certifications. 